Proceedings

\title{
Comparison of the Consumption of N-3 and N-6 Acids by Adults Following a Vegetarian and Traditional Diet ${ }^{\dagger}$
}

\author{
Marcin Lukasiewicz *, Agnieszka Filipiak-Florkiewicz, Adam Florkiewicz, Kinga Topolska, Gabriela Zięć \\ and Barbara Czosnowska
}

Citation: Lukasiewicz, M.; FilipiakFlorkiewicz, A.; Florkiewicz, A.; Topolska, K.; Zięć, G.; Czosnowska, B. Comparison of the

Consumption of N-3 and N-6 Acids by Adults Following a Vegetarian and Traditional Diet. Proceedings 2021, 70, 44. https:// doi.org/10.3390/foods_2020-08471

Published: 18 November 2020

Publisher's Note: MDPI stays neutral with regard to jurisdictional claims in published maps and institutional affiliations.

Copyright: (c) 2020 by the authors. Licensee MDPI, Basel, Switzerland. This article is an open access article distributed under the terms and conditions of the Creative Commons Attribution (CC BY) license (http://creativecommons.org/licenses/by/4.0/).
Faculty of Food Technology, University of Agriculture in Krakow, ul. Balicka 122, PL-30-149 Krakow, Poland; agnieszka.filipiak-florkiewicz@urk.edu.pl (A.F.-F.); adam.florkiewicz@urk.edu.pl (A.F.); rrtopols@cyf-kr.edu.pl (K.T.); gabriela.ziec@urk.edu.pl (G.Z.); pallavicasia@gmail.com (B.C.)

* Correspondence: rrlukasi@cyf-kr.edu.pl

† Presented at the 1st International Electronic Conference on Food Science and Functional Foods, 10-25 November 2020; Available online: https://foods_2020.sciforum.net/.

\begin{abstract}
The aim of this study was to compare the consumption of n-3 and n-6 acids by adults using a vegetarian and traditional diet. The study was conducted on a group of 170 adults (18-50 years old), including 94 respondents following a traditional diet (56 women and 38 men) and 76 people following a vegetarian diet (52 women and 24 men). The research used the method of a 24$\mathrm{h}$ interview conducted four days a week (Monday, Wednesday, Friday, Sunday). The record included the quantity and quality of individual meals and drinks. The study showed that people consuming traditional diets fulfilled the demand for the fatty acids eicosapentaenoic acid (EPA) and docosahexaenoic acid (DHA) to a significantly higher degree than people following a vegetarian diet. Men preferring the traditional diet fulfilled the daily requirement for DHA and EPA acids significantly better than women. A reverse tendency was found among respondents who consumed a vegetarian diet. The supply of linolenic acid (LA) in the vegetarian diet exceeded the recommended daily amount (especially among men), whereas with the traditional diet it was too low in relation to the recommended values.
\end{abstract}

Keywords: n-3 acid; n-6 acid; vegetarian diet; survey research

\section{Introduction}

Life is inextricably linked with food. With increasing prosperity and access to food products from almost all over the world, consumers are becoming more interested in what they eat and how it affects their bodies. Some scientific theories are quickly questioned, whereas others face the test of time, bringing information that may reveal part of the phenomena underlying the functioning of the human body. The influence of the world on this functioning must also be acknowledged, including lifestyle choices and food consumed. In this study, we describe n-3 and n-6 acids in terms of their effects on the human body, and examine whether and to what extent the consumption of these acids differs depending on diet (comparing a vegetarian diet and a traditional diet). In addition to key issues such as the overall effect of n-3 and n-6 acids on improving the health of people suffering from diseases such as type 2 diabetes, atherosclerosis, hypertension and coronary heart disease, attention was also paid to the extent to which the diet models studied are able to meet the demand for some essential fatty acids (in line with the guidelines of the Polish Food and Nutrition Institute).

Accordingly, the aim of the study was to compare the consumption of n-3 and n-6 acids by adults following a vegetarian and a traditional diet. 


\section{Methods}

The study was conducted in a group of 170 adults (18-50 years old), including 94 respondents following a traditional diet (56 women and 38 men) and 76 people following a vegetarian diet (52 women and 24 men). We used the method of a 24-h interview from four days a week (Monday, Wednesday, Friday, Sunday). The record included the quantity and quality of individual meals and drinks. The respondents defined the portion size with the help of the "Album of photos and food products" [1]. In order to clarify doubts, the results were checked by the interviewer and consulted with the interviewee. The respondents also completed a questionnaire containing questions about gender, body weight, height, supplementation used and place of residence. The intakes of individual ingredients were calculated using Dieta software, version 5.0, developed by the National Food and Nutrition Institute in Warsaw (Poland). The software contains a food composition database based on Polish food composition tables. However, for the analysis of the results, MS Excel software was used, in which the compatibility test was performed and the relationship between the consumption of n-3 and n-6 acids was estimated depending on gender and the type of diet followed. The Dieta 5.0 program displayed the results for individual fatty acids in relation to their sum formula; therefore, the value for $\gamma$-linolenic acid (GLA) and $\alpha$-linolenic acid (ALA) was given as a sum (C18: 3 ). In order to be able to perform a comparative analysis of the consumption of fatty acids, the result of which was given in grams, with the energy obtained from the diet, the result of which was given in kilocalories, the formula that $1 \mathrm{~g}$ equals $9 \mathrm{kcal}$ of fat (fatty acids) was used. The data recommended by the Polish Food and Nutrition Institute were used to calculate the percentage of the recommended daily intake for eicosapentaenoic acid (EPA) and docosahexaenoic acid (DHA). Statistical significance was determined using the Chi-squared test (MsExcel). For normally distributed variables, the unpaired Student's $t$-test was applied to investigate statistically significant differences, whereas for skewed variables, the non-parametric Mann-Whitney $U$ test was used due to the uneven gender balance. The significance level was set at $p \leq 0.05$.

\section{Results and Discussion}

The conducted research has shown that there are no significant relationships between diet and gender in relation to the consumption of individual fatty acids and total fatty acids. Hence, the discussed results are presented as the average consumption of the population. Statistically significant differences are shown using the Chi-squared test only in the case of the recommended daily consumption of linolenic acid (LA), DHA and EPA for gender and diet.

As an example, it is worth emphasizing that the average daily consumption of individual fatty acids among men using the traditional diet was $0.05 \mathrm{~g}$ for EPA, DHA $0.13 \mathrm{~g}$, LA $7.06 \mathrm{~g}$, the sum of GLA and ALA $1.39 \mathrm{~g}$ and arachidonic acid (AA) $0.09 \mathrm{~g}$. Among women, the same model of nutritional consumption of the above-mentioned acids was $0.06,0.17,6.91,1.22$ and $0.13 \mathrm{~g}$. On the other hand, the average daily consumption of individual fatty acids among men preferring a vegetarian diet was: EPA $0.01 \mathrm{~g}$, DHA $0.05 \mathrm{~g}$, LA $8.53 \mathrm{~g}$, GLA and ALA $1.99 \mathrm{~g}$ and AA $0.02 \mathrm{~g}$. Fatty acid intake among women was found at the level of: EPA 0.002 g, DHA 0.02 g, LA 12.84 g, GLA and ALA $3.05 \mathrm{~g}$ and AA $0.02 \mathrm{~g}$ (Table 1). The statistical analysis did not show statistically significant differences $(p>0.05)$ in the amount of acids consumed and the gender of the respondents or the type of their diet. The obtained results differ from the available literature data, showing slightly higher values for EPA and DHA and lower parameters for LA acids (regardless of gender) [2]. 
Table 1. Daily fatty acid consumption among women and men following traditional and vegetarian diets.

\begin{tabular}{|c|c|c|c|c|c|c|c|c|c|}
\hline \multirow{3}{*}{$\begin{array}{l}\text { Fatty } \\
\text { Acid }\end{array}$} & \multirow{3}{*}{ Gender } & \multicolumn{4}{|c|}{ Traditional Diet } & \multicolumn{4}{|c|}{ Vegetarian Diet } \\
\hline & & \multirow{2}{*}{$\mathrm{X} \pm \mathrm{SD}$} & \multicolumn{3}{|c|}{ Consumption } & \multirow{2}{*}{$\mathrm{X} \pm \mathrm{SD}$} & \multicolumn{3}{|c|}{ Consumption } \\
\hline & & & Min. & Max. & Me & & Min. & Max. & Me \\
\hline \multirow{2}{*}{ EPA } & Men & $0.05 \pm 0.23$ & 0.00 & 3.03 & 0.00 & $0.01 \pm 0.08$ & 0.00 & 1.03 & 0.00 \\
\hline & Women & $0.06 \pm 0.22$ & 0.00 & 1.47 & 0.00 & $0.002 \pm 0.02$ & 0.00 & 0.13 & 0.00 \\
\hline \multirow{2}{*}{ DHA } & Men & $0.13 \pm 0.37$ & 0.00 & 4.75 & 0.04 & $0.05 \pm 0.23$ & 0.00 & 3.19 & 0.00 \\
\hline & Women & $0.17 \pm 0.57$ & 0.00 & 4.45 & 0.03 & $0.02 \pm 0.05$ & 0.00 & 0.32 & 0.00 \\
\hline \multirow{2}{*}{ LA } & Men & $7.06 \pm 4.99$ & 0.48 & 33.13 & 5.67 & $8.53 \pm 6.49$ & 0.69 & 47.53 & 7.12 \\
\hline & Women & $6.91 \pm 4.78$ & 0.62 & 36.52 & 5.82 & $12.84 \pm 8.77$ & 2.46 & 56.69 & 10.66 \\
\hline \multirow{2}{*}{$\begin{array}{l}\text { GLA + } \\
\text { ALA }\end{array}$} & Men & $1.39 \pm 1.71$ & 0.12 & 14.73 & 0.92 & $1.99 \pm 2.48$ & 0.09 & 16.48 & 1.10 \\
\hline & Women & $1.22 \pm 1.20$ & 0.16 & 9.10 & 0.87 & $3.05 \pm 3.92$ & 0.1534 & 23.66 & 1.70 \\
\hline \multirow{2}{*}{$\mathrm{AA}$} & Men & $0.09 \pm 0.12$ & 0.00 & 1.21 & 0.04 & $0.02 \pm 0.06$ & 0.00 & 0.49 & 0.00 \\
\hline & Women & $0.13 \pm 0.15$ & 0.00 & 0.81 & 0.03 & $0.01 \pm 0.08$ & 0.00 & 0.23 & 0.00 \\
\hline
\end{tabular}

Min. - minimal value; Max. - maximal value; Me-median; $\mathrm{X}$-average; SD-standard deviation.

The average daily intake of $\mathrm{n}-3$ fatty acids in the traditional diet was $1.57 \mathrm{~g}$ among women, and $1.46 \mathrm{~g}$ among men. Respondents preferring a vegetarian diet consumed the abovementioned acids in quantities of 2.05 and $3.08 \mathrm{~g}$ (Table 2). Statistical analysis showed no significant differences in the uptake of these acids either by gender or by type of diet. N-3 acids in the traditional diet constituted $2.71 \%$ (women) and $2.20 \%$ (men), and in the vegetarian diet $4.42 \%$ (women) and $5.51 \%$ (men) of total fat during the day (Table 2). In the case of the traditional diet, a slightly higher consumption of these fatty acids was recorded among women, whereas the vegetarian diet among men showed a higher consumption. Statistical analysis showed no significant differences in the uptake of n-3 acids depending on the feeding model. In the study by Jabłonowska et al. [3] the mean daily consumption of n-3 acids among women following a traditional diet was similar to the presented data and amounted to $1.58 \pm 1.09 \mathrm{~g}$, and among men it was higher than the results discussed ( $2.24 \pm 1.24 \mathrm{~g})$. It demonstrated [2] a higher mean daily consumption of $\mathrm{n}-3$ fatty acids with a traditional diet, amounting to $2.48 \mathrm{~g}$ in girls, and $2.53 \mathrm{~g}$ in boys.

Table 2. Daily n-3 and n-6 acid consumption in respondents following traditional and vegetarian diets.

\begin{tabular}{|c|c|c|c|c|c|c|c|c|}
\hline \multirow{3}{*}{ Gender } & \multicolumn{4}{|c|}{ Traditional Diet } & \multicolumn{4}{|c|}{ Vegetarian Diet } \\
\hline & \multirow{2}{*}{$X \pm S D$} & \multicolumn{3}{|c|}{ Consumption } & \multirow{2}{*}{$X \pm S D$} & \multicolumn{3}{|c|}{ Consumption } \\
\hline & & Min. & Max. & $\mathrm{Me}$ & & Min. & Max. & $\mathrm{Me}$ \\
\hline \multicolumn{9}{|c|}{ Average daily consumption of $n-3$ acids depending on gender and nutrition model $(\mathrm{g} / \mathrm{d})$} \\
\hline Women & $1.57 \pm 1.84$ & 0.17 & 14.92 & 1.05 & $2.05 \pm 2.48$ & 0.20 & 16.48 & 1.16 \\
\hline Men & $1.46 \pm 1.45$ & 0.16 & 9.19 & 0.99 & $3.08 \pm 3.91$ & 0.16 & 23.66 & 1.70 \\
\hline \multicolumn{9}{|c|}{ Percentage of total fat content of acids from the $n-3$ family } \\
\hline Women & $2.71 \pm 2.18$ & 0.67 & 17.38 & 2.03 & $4.42 \pm 3.91$ & 0.46 & 25.21 & 3.21 \\
\hline Men & $2.20 \pm 1.74$ & 0.48 & 12.98 & 1.73 & $5.51 \pm 6.06$ & 0.82 & 40.21 & 3.85 \\
\hline \multicolumn{9}{|c|}{ Average daily consumption of $n-6$ acids depending on gender and nutrition model (g/d) } \\
\hline Women & $8.53 \pm 6.15$ & 0.70 & 45.17 & 6.83 & $10.54 \pm 8.11$ & 0.81 & 60.25 & 8.42 \\
\hline Men & $8.26 \pm 5.68$ & 0.80 & 44.79 & 7.03 & $15.91 \pm 10.35$ & 2.69 & 58.76 & 13.47 \\
\hline \multicolumn{9}{|c|}{ Percentage of total fat content of acids from the $n-6$ family } \\
\hline Women & $15.17 \pm 6.09$ & 4.25 & 36.31 & 14.15 & $23.16 \pm 10.10$ & 2.34 & 51.77 & 22.12 \\
\hline Men & $12.59 \pm 5.11$ & 4.29 & 39.31 & 11.69 & $28.21 \pm 10.59$ & 10.64 & 56.96 & 27.40 \\
\hline
\end{tabular}

Min. - minimal value; Max. - maximal value; Me-median; X-average; SD-standard deviation.

The average daily consumption of n- 6 fatty acids with the traditional diet was $8.53 \mathrm{~g}$ among women, and $8.26 \mathrm{~g}$ among men. In the case of a vegetarian diet, these values were 
10.54 and $15.91 \mathrm{~g}$, respectively (Table 2). There was no significant differentiation in the uptake of these acids depending on the type of diet and gender. N-6 fatty acids in the traditional diet accounted for $15.17 \%$ (women) and $12.59 \%$ (men), and in the vegetarian diet $23.16 \%$ (women) and $28.21 \%$ (men) of total fat consumed during the day (Table 2).

In the traditional diet, the consumption of $\mathrm{n}-6$ fatty acids among both sexes was almost identical, whereas in the vegetarian diet it was slightly higher among men. In the studies published by Stachura et al. [2] the mean daily consumption of n-6 acids was higher and was $10.1 \mathrm{~g}$ among girls following the traditional diet, and $10.9 \mathrm{~g}$ among boys.

The data on fat and energy supply (Table 3 ) show that the average daily energy value of the traditional diet was $1907.92 \pm 904.65 \mathrm{kcal}$ among women, and $2067.33 \pm 811.36 \mathrm{kcal}$ among men. On the other hand, the energy value of a vegetarian food ration was slightly lower for both women $(1475.44 \pm 600.81 \mathrm{kcal})$ and men $(1687.59 \pm 665.87 \mathrm{kcal})$. However, according to Jabłonowska et al. [3] the average energy value of the daily traditional ration was $1700 \pm 712 \mathrm{kcal}$, with $1548 \pm 611 \mathrm{kcal}$ among women and $2199 \pm 834$ among men. In the study by Kornek et al. the average amount of energy per day among women on vegan and lacto-ovo-vegetarian diets was slightly higher than in the study in question and amounted to 1670-1692 kcal. Davey et al. [4] showed that women who preferred the traditional diet supplied less energy per day from food, only $1686 \mathrm{kcal}$, whereas higher results were obtained by men on the traditional diet $(2192 \mathrm{kcal})$ and women and men on a vegetarian diet (1686 kcal and $2097 \mathrm{kcal}$, respectively). The average daily total fat consumption with the traditional diet was $57.92 \pm 37.87 \mathrm{~g}$ among women, and $69.61 \pm 44.09 \mathrm{~g}$ among men. In turn, in the vegetarian diet among women it was $48.07 \pm 42.61 \mathrm{~g}$, and among men $57.21 \pm 30.84 \mathrm{~g}$. Statistical analysis did not show a relationship between fat consumption and gender or diet. Jabłonowska et al. [3] showed that the average daily fat consumption among women with a traditional diet was $56.0 \pm 27.9 \mathrm{~g}$, so it was similar to the presented data for this sex. However, among men it was higher and amounted to 93.5 $\pm 46.1 \mathrm{~g}$.

Table 3. Average supply of total energy and fat with traditional and vegetarian diets.

\begin{tabular}{|c|c|c|c|c|c|c|c|c|}
\hline \multirow{3}{*}{ Gender } & \multicolumn{4}{|c|}{ Traditional Diet } & \multicolumn{4}{|c|}{ Vegetarian Diet } \\
\hline & \multirow{2}{*}{$\mathrm{X} \pm \mathrm{SD}$} & \multicolumn{3}{|c|}{ Consumption } & \multirow{2}{*}{$\mathrm{X} \pm \mathrm{SD}$} & \multicolumn{3}{|c|}{ Consumption } \\
\hline & & Min. & Max. & Me & & Min. & Max. & Me \\
\hline \multicolumn{9}{|c|}{ Average energy supply $(\mathrm{kcal} / \mathrm{d}$ ) with traditional and vegetarian diets } \\
\hline Women & $\begin{array}{c}1907.92 \pm \\
904.65 \\
\end{array}$ & 578.33 & 6079.49 & 1755.49 & $1475.44 \pm 600.81$ & 566.18 & 6223.32 & 1412.66 \\
\hline Men & $\begin{array}{c}2067.33 \pm \\
811.36\end{array}$ & 341.12 & 4360.47 & 1987.33 & $1687.59 \pm 665.87$ & 695.78 & 5249.73 & 1598.38 \\
\hline \multicolumn{9}{|c|}{ Average total fat supply $(\mathrm{g} / \mathrm{d})$ in traditional and vegetarian diets } \\
\hline Women & $57.92 \pm 37.87$ & 4.70 & 275.56 & 49.98 & $48.07 \pm 42.61$ & 5.86 & 476.89 & 43.25 \\
\hline Men & $69.61 \pm 44.09$ & 4.32 & 275.50 & 59.64 & $57.21 \pm 30.84$ & 8.22 & 183.65 & 53.00 \\
\hline \multicolumn{9}{|c|}{ The percentage of total fat in the daily caloric supply } \\
\hline Women & $27.82 \pm 11.28$ & 3.87 & 64.62 & 27.28 & $27.54 \pm 11.77$ & 6.35 & 89.81 & 26.49 \\
\hline Men & $29.28 \pm 10.60$ & 6.29 & 56.96 & 28.99 & $30.03 \pm 10.61$ & 8.79 & 66.97 & 30.01 \\
\hline
\end{tabular}

Min. - minimal value; Max. - maximal value; Me - median; X-average; SD-standard deviation.

The sum of polyunsaturated fatty acids analyzed in the study per day in the traditional diet among women was $10.10 \pm 7.58 \mathrm{~g}$, and among men $9.72 \pm 6.70 \mathrm{~g}$. On the other hand, in the vegetarian diet it was $12.59 \pm 10.07 \mathrm{~g}$ and $18.99 \pm 12.97 \mathrm{~g}$, respectively (Table 4). The statistical analysis did not show any significant differentiation of this parameter depending on the sex of the respondents and their diet. Slightly higher results were obtained by Stachura et al. [2]. However, in the research of Jabłonowska et al. [3] the average daily polyunsaturated fatty acids (PUFA) intake by women on a traditional diet was 
slightly lower than the presented data and amounted to $9.6 \pm 5.9 \mathrm{~g}$, whereas among men it was higher and equaled $13.6 \pm 6.8 \mathrm{~g}$.

In the present study, PUFAs provided $4.90 \%$ of daily energy in the traditional diet among women and $4.13 \%$ among men. On the other hand, in the vegetarian diet, this parameter accounted for $7.38 \%$, respectively, and $10.21 \%$ of total energy among men (Table 4). In this case, the statistical analysis also showed significant differentiation both by gender and by diet. Similar data were obtained by Stachura et al. [2], who showed that the energy from PUFA among girls using the traditional diet was $4.9 \%$, whereas among boys it was $5.0 \%$. In the research by Jabłonowska et al. [3] the average daily PUFA consumption among women and men consuming the traditional diet was slightly higher and amounted to $5.6 \%$ of energy. In a study by Davey [4] et al., PUFA in the traditional diet provided $5.19 \%$ of energy among women, and $5.21 \%$ among men. The vegetarian diet, on the other hand, provided $5.29 \%$ (among women) and 5.67\% (among men) of total energy with PUFA.

Table 4. Supply of PUFA with traditional and vegetarian diets.

\begin{tabular}{|c|c|c|c|c|c|c|c|c|}
\hline \multirow{3}{*}{ Gender } & \multicolumn{4}{|c|}{ Traditional Diet } & \multicolumn{4}{|c|}{ Vegetarian Diet } \\
\hline & \multirow{2}{*}{$X \pm S D$} & \multicolumn{3}{|c|}{ Consumption } & \multirow{2}{*}{$\mathrm{X} \pm \mathrm{SD}$} & \multicolumn{3}{|c|}{ Consumption } \\
\hline & & Min. & Max. & Me & & Min. & Max. & Me \\
\hline \multicolumn{9}{|c|}{ Average daily PUFA supply in traditional and vegetarian diets $(\mathrm{g} / \mathrm{d})$} \\
\hline Women & $10.10 \pm 7.58$ & 0.92 & 57.29 & 8.01 & $12.59 \pm 10.07$ & 1.25 & 72.98 & 9.95 \\
\hline Men & $9.72 \pm 6.70$ & 0.97 & 53.08 & 8.11 & $18.99 \pm 12.97$ & 2.85 & 67.45 & 15.66 \\
\hline \multicolumn{9}{|c|}{ Percentage of daily energy supply supplied by PUFAs } \\
\hline Women & $4.90 \pm 2.91$ & 0.38 & 18.29 & 4.12 & $7.38 \pm 4.64$ & 0.97 & 33.51 & 6.45 \\
\hline Men & $4.13 \pm 1.90$ & 1.11 & 12.39 & 3.59 & $10.21 \pm 6.65$ & 2.33 & 40.96 & 9.22 \\
\hline
\end{tabular}

People eating the traditional diet did not meet the recommended daily allowance. The percentage of the recommended daily consumption, which according to the IŻŻ (Polish Institute of Food and Nutrition) amounts to $4 \%$ of the daily energy requirement for LA (n-6) [5], was $85.91 \%$ among women and $73.12 \%$ of men consuming a traditional diet. On the other hand, among the respondents preferring a vegetarian diet, it was $125.92 \%$ and $168.69 \%$, respectively (Table 5). Statistical analysis showed that there is a significant differentiation in the fulfillment of energy demand from LA acid, depending on both gender and diet. In the study by Kornek et al. [6] the obtained results were significantly lower than those presented and amounted to $70 \%-83 \%$ of the daily demand for LA for vegans and lacto-ovovegetarians, whereaswomen following the traditional diet covered only $44 \%$ of the demand.

Table 5. Percentage of the recommended daily intake of linolenic acid (LA) and the sum of eicosapentaenoic acid (EPA) and docosahexaenoic acid (DHA).

\begin{tabular}{|c|c|c|c|c|c|c|c|c|}
\hline \multirow{3}{*}{ Gender } & \multicolumn{4}{|c|}{ Traditional Diet } & \multicolumn{4}{|c|}{ Vegetarian Diet } \\
\hline & \multirow{2}{*}{$\mathrm{X} \pm \mathrm{SD}$} & \multicolumn{3}{|c|}{ Consumption } & \multirow{2}{*}{$\mathrm{X} \pm \mathrm{SD}$} & \multicolumn{3}{|c|}{ Consumption } \\
\hline & & Min. & Max. & Me & & Min. & Max. & Me \\
\hline \multicolumn{9}{|c|}{ Percentage of the recommended daily allowance for LA acid } \\
\hline Women & $5.91 \pm 49.39$ & 5.06 & 360.10 & 76.05 & $125.92 \pm 73.34$ & 13.37 & 450.71 & 113.09 \\
\hline Men & $73.12 \pm 32.53$ & 14.87 & 188.79 & 64.93 & $168.69 \pm 85.44$ & 47.48 & 497.88 & 150.85 \\
\hline \multicolumn{9}{|c|}{ Percentage of the recommended daily intake for EPA and DHA } \\
\hline Women & $\begin{array}{c}73.14 \pm \\
242.05\end{array}$ & 0.00 & 3112.00 & 18.52 & $24.18 \pm 124.10$ & 0.00 & 1687.64 & 0.00 \\
\hline Men & $\begin{array}{c}93.82 \pm \\
309.69\end{array}$ & 0.00 & 2369.20 & 17.02 & $9.59 \pm 24.12$ & 0.00 & 178.96 & 0.00 \\
\hline
\end{tabular}

Min. - minimal value; Max. - maximal value; Me-median; X-average; SD - standard deviation. 
The percentage of the daily intake recommended by the Institute of Food and Drug Administration for EPA and DHA (n-3) acids is $250 \mathrm{mg} / \mathrm{d}$ [5]. In the analyzed study, the intake of these acids with a traditional diet was demonstrated, allowing women to meet the needs of $73.14 \%$ and $93.82 \%$ by men. Even lower values were found in the group of respondents consuming a vegetarian diet. These values were only $24.18 \%$ among women and $9.59 \%$ among men (Tables 5). In the case of these acids, the level of achievement of the recommendations differed significantly depending on gender and diet. In the presented study, none of the groups managed to meet the recommended daily intake of the sum of EPA and DHA acids. Statistical analysis showed that in the case of a vegetarian diet, these results were significantly lower than the data obtained for people on a traditional diet. As well as among the respondents consuming a vegetarian diet, men obtained a significantly lower result than women, whereas in relation to the traditional diet, the opposite correlation was shown. In the data presented by Kornek et al. [6] there is a similar relationship between people following traditional and vegetarian diets. In the cited study, none of the vegans and lacto-ovo-vegetarians covered the demand for DHA + EPA. In the case of women on a traditional diet, only $25 \%$ of them consumed the appropriate amount of these acids.

\section{Conclusions}

The analyzed data show that the average supply of n-3 fatty acids in grams per day did not differ depending on the diet used. The mean daily consumption of $n-6$ fatty acids in grams/day was similar among respondents eating traditional and vegetarian diets. The consumption ratios of n-6: n-3 fatty acids were slightly lower among those consuming a vegetarian diet than in a traditional diet. The study showed that people consuming traditional diets fulfilled the demand for EPA and DHA fatty acids to a significantly higher degree than people following a vegetarian diet. Men preferring the traditional diet fulfilled the daily requirement for DHA and EPA acids significantly better than women. The opposite tendency was found among respondents who consumed a vegetarian diet. The supply of LA with the vegetarian diet exceeded the recommended daily amount (especially among men), whereas in the traditional diet it was too low in relation to the recommended values. On the basis of the presented research results, it should be stated that in both people consuming a vegetarian and a traditional diet, the supply of $n-3$ and $n-6$ acids should be modified to ensure an adequate amount of these nutrients in both study groups. Particularly, the supply of n-3 acids should be increased in order to maintain the best n3:n-6 ratio. Such a modification would to some extent help prevent diet-related diseases such as type 2 diabetes, atherosclerosis, hypertension or ischemic heart disease, among others, as well as bringing many other positive health consequences for the body [7].

Institutional Review Board Statement: The experiments conducted as part of the research did not require the approval of the Institutional Review Board at the time of their conduct.

Informed Consent Statement: Informed consent was obtained from all subjects involved in the study.

Data Availability Statement: Data available on request.

\section{References}

1. Szponar, L.; Wolnicka, K.; Rychlik, E. Album of Photographs of Food Products and Dishes; Food and Nutrition Institute: Warsaw, Poland, 2008.

2. Stachura, A.; Pisulewski, P.M.; Kopeć, A.; Leszczyńska, T.; Bieżanowska-Kopeć, R. Estimating the consumption of total fats and fatty acids by rural youth in Beskid Żywiecki. Food Sci. Technol. Qual. 2009, 5, 119-131. (In Polish)

3. Jabłonowska, B.; Dłużniewska, A.; Jarosz, A.; Nowicka, G. Assessment of the consumption of n-3 polyunsaturated fatty acids among healthy adults in relation to the current nutrition standards. Ann. Natl. Inst. Hyg. 2011, 62, 389-396.

4. Davey, K.G.; Spencer, E.A.; Appleby, P.N.; Allen, N.E.; Knox, K.H.; Key, T.J. EPIC-Oxford: Lifestyle characteristics and nutrient intakes in a cohort of 33883 meat-eaters and 31546 non meat-eaters in the UK. Public Health Nutr. 2001, 6, $259-268$.

5. Jarosz, M. Fat. In Nutrition Standards for the Polish Population; Food and Nutrition Institute: Warsaw, Poland, $2017 ;$ pp. 56-72. 
6. Kornek, A.; Kucharska, A.; Kamela, K. Analysis of the fatty acid profile of vegetarian and non-vegetarian diets in the context of the prevention of selected diet-related diseases. Wiad. Lek. 2016, 69 (3 Pt 2), 483-488.

7. Śliż, D.; Zgliczyński, W.; Szeligowska, J.; Rostkowska, O.; Pinkas, J. Modification of dietary habits in the prevention of civilization diseases. Adv. Med. Sci. 2016, 29, 344-349. 